\title{
TEMPORAL VARIATION OF RADIOCARBON CONCENTRATION IN AIRBORNE PARTICULATE MATTER IN TOKYO
}

\author{
Ken Shibata $^{1} \cdot$ Michio Endo $^{1} \cdot$ Naomichi Yamamoto ${ }^{1}$ Jun Yoshinaga $^{1,2} \cdot$ Yukio Yanagisawa $^{1} \bullet$ \\ Osamu Endo ${ }^{3} \cdot$ Sumio Goto $^{4} \cdot$ Minoru Yoneda ${ }^{4}$ Yasuyuki Shibata ${ }^{4}$ Masatoshi Morita $^{4}$
}

ABSTRACT. The temporal radiocarbon variation (in terms of percent Modern Carbon: $\mathrm{pMC}$ ) of size-fractionated airborne particulate matter (APM) collected in Tokyo between April 2002 and February 2003 was analyzed in order to get an insight into the sources of carbonaceous particles. Results indicated significant biogenic origins (approximately $40 \mathrm{pMC}$ on average). In general, the seasonal and particle size variations in pMC were relatively small, with 2 exceptions: elevated pMC in coarse particles in April and October 2002, and relatively low pMC in the finest particle size fraction collected in August 2002. The former finding could be tentatively attributed to the abundance of coarse particles of biological origins, such as pollen; the latter might be due to an increased fraction of anthropogenic secondary particles.

\section{INTRODUCTION}

Health and meteorological effects caused by airborne particulate matter (APM) have been extensively investigated (Dockery et al. 1993; Charlson et al. 1992). The major emission sources of the APM in Tokyo are thought to include diesel exhaust, gas-to-particle conversion, road dust, iron and steel industries, fuel oil combustion, natural (soil, marine, biogenic emissions, and so on), and refuse incineration origins (Yoshizumi 1991). A chemical mass balance method in conjunction with the use of atmospheric tracers, such as metals and ions, has been one of the major approaches for the source apportionment of the APM (Gordon 1988). Radiocarbon has been introduced as a promising measure to determine the mixing ratio of fossil and biomass components (Currie 2000). Since ${ }^{14} \mathrm{C} \mathrm{com}-$ pletely decays to radioactive decay during the fossilization period, fossil fuels do not contain ${ }^{14} \mathrm{C}$. Therefore, the amount of ${ }^{14} \mathrm{C}$ expressed in a unit of percent modern carbon (pMC) (Stuiver and Polach 1977) can approximate the biogenic contribution of target materials, although the ambient ${ }^{14} \mathrm{C}$ excess from atmospheric bomb tests of the 1950s (Currie et al. 1989) needs to be corrected for more accurate source dissection. Since ${ }^{14} \mathrm{C}$ for the APM source apportionment was first introduced by Clayton et al. (1955), various studies have been performed to characterize APM using ${ }^{14} \mathrm{C}$ as a tracer to offer quantitative distinctions between fossil and biomass origins (Currie et al. 1989; Hildemann et al. 1994; Currie et al. 1997; Klinedinst et al. 1999; Weissenbök et al. 2000; Lemire et al. 2002; Reddy et al. 2002). These studies indicated biogenic sources contributed significantly to the total and fine particles in the USA. In our previous study (M Endo, J Yoshinaga, N Yamamoto, $\mathrm{Y}$ Yanagisawa, O Endo, S Goto, M Yoneda, Y Shibata, M Moriata, unpublished data), the pMC value of the APM collected in Tokyo was found to be approximately 30. In this paper, seasonal variations in ${ }^{14} \mathrm{C}$ concentrations in the size-fractionated APM are further reported to provide a detailed insight into the sources of carbonaceous particles.

\footnotetext{
${ }^{1}$ Institute of Environmental Studies, The University of Tokyo, Hongo 7-3-1, Bunkyo-ku, Tokyo 113-0033, Japan.

${ }^{2}$ Corresponding author. Email: junyosh@k.u-tokyo.ac.jp.

${ }^{3}$ National Institute of Public Health, 4-6-1 Shirokanedai, Minato-ku, Tokyo, 108-8638, Japan.

${ }^{4}$ National Institute for Environmental Studies, 16-2 Onogawa, Tsukuba-shi, 305-8506, Japan.
}

(C) 2004 by the Arizona Board of Regents on behalf of the University of Arizona Proceedings of the 18th International Radiocarbon Conference, edited by N Beavan Athfield and R J Sparks RADIOCARBON, Vol 46, Nr 1, 2004, p 485-490 


\section{MATERIALS AND METHODS}

\section{Sample Collection}

A high-volume Andersen sampler with 5 cascaded stages $(<1.3,1.3-2.2,2.2-3.8,3.8-7.9$, and $>7.9 \mu \mathrm{m}$ of aerodynamic diameter) (Model AH-600, Sibata Scientific Technology Ltd., Tokyo, Japan) was used for the size-fractionated APM collection. Quartz filters (2500QAST, Pallflex; about $30 \mathrm{~cm}$ in diameter) to be loaded in the Andersen sampler were pre-combusted at $850{ }^{\circ} \mathrm{C}$ to remove carbon contamination before sampling. The APM samples were collected bimonthly from April 2002 to February 2003 for the duration of 7 days on the rooftop (approximately $20 \mathrm{~m}$ from the ground level) of the National Institute of Public Health (NIPH) in Minato-ku, located in the center of the metropolitan Tokyo. The sampler was operated at a nominal flow rate of $566 \mathrm{~L} / \mathrm{min}$ (total air volume $5705 \mathrm{~m}^{3}$ ). The sampled filters were kept in a freezer until the ${ }^{14} \mathrm{C}$ analysis.

\section{${ }^{14} \mathrm{C}$ Measurement}

The APM collected on a quartz filter (minimum $1 \mathrm{mg}$ carbon) was combusted in a specially designed large-volume quartz tube with $5.0 \mathrm{~g}$ copper oxide, $2.5 \mathrm{~g}$ copper, and $0.1 \mathrm{~g}$ silver foil. After combustion at $850^{\circ} \mathrm{C}$ for $2 \mathrm{hr}$, the resultant gas was cryogenically purified to obtain $\mathrm{CO}_{2}$, which was subsequently heated to $650^{\circ} \mathrm{C}$ for $8 \mathrm{hr}$ with an iron catalyst and hydrogen in a graphite reaction tube (Kitagawa et al. 1993). The produced graphite was packed into targets for accelerator mass spectrometry (AMS) measurement. The AMS analysis was undertaken at the National Institute for Environmental Studies Tandem Accelerator for Environmental Research and Radiocarbon Analysis (NIES-TERRA) Facility (Tanaka et al. 2000). For ${ }^{14} \mathrm{C}$ measurements, a certified reference material from the National Institute of Standards and Technology (NIST SRM 4990c, Hox II, USA) was used as a standard (certified pMC value of 134.07). Precision of pMC analysis at the NIES-TERRA was evaluated by repeated analyses of the Hox II and the result was $134.21 \pm 0.21(\mathrm{n}=10)$ (M Endo, J Yoshinaga, N Yamamoto, Y Yanagisawa, O Endo, S Goto, M Yoneda, Y Shibata, M Moriata, unpublished data). The absolute concentrations of biomass and fossil carbons, in addition to their ratios, were calculated with information of the $\mathrm{CO}_{2}$ pressure generated during the purification process, since it corresponds with absolute carbon content in the APM sample. The surface of the filter for coarse particle fraction $(>7.9 \mu \mathrm{m})$ was observed with a scanning electron microscope (SEM), and the numbers of pollen in $325 \times 225-\mu \mathrm{m}$ area units were counted.

\section{RESULTS AND DISCUSSION}

The annual means and standard deviations of ${ }^{14} \mathrm{C}$ concentrations in the size-fractionated APM were $36.4 \pm 5.3,43.1 \pm 4.9,44.5 \pm 7.1,49.0 \pm 11.0$, and $44.8 \pm 8.8 \mathrm{pMC}$ for the following particles, respectively, $<1.3,1.3-2.2,2.2-3.8,3.8-7.9$, and $>7.9 \mu \mathrm{m}$. There is an increasing tendency in pMC in accordance with an increase of the particle size (Figure 1). The overall mass-weighted mean pMC in an entire particle size range through the year was 40.2. A study conducted in Los Angeles (USA) showed that contemporary carbon constituted $20-43 \%$ of the fine particulate matter (Hildemann et al. 1994). Therefore, the present results clearly demonstrated that a certain amount of modern (biomass) carbon also contributed to the APM in metropolitan Tokyo as was observed in Los Angeles. It should be noted, however, that our study used the unit of pMC for the purpose of characterizing seasonal and size-fractional trends instead of using the fraction of contemporary carbon for which the ambient ${ }^{14} \mathrm{C}$ excess needed to be corrected. The potential sources of the biomass carbon include the emissions from the refuse incineration and secondary particle formation from atmospheric oxidation of volatile organic compounds (VOCs) emitted from vegetation. The observed pMC values were higher than that of the reference APM (33.7 pMC), the composite of total 
suspended particles collected by an electrostatic precipitator over 2 yr between 1997 and 2000 at the same sampling site (M Endo, J Yoshinaga, N Yamamoto, Y Yanagisawa, O Endo, S Goto, M Yoneda, Y Shibata, M Moriata, unpublished). The pMC values observed in each particle size fraction distributed in narrow range around $40 \mathrm{pMC}$ through the year with 2 exceptions. First, pMC elevation was observed in coarse particles collected in April and October 2002. Second, relatively low pMC was found in the finest fraction collected in August 2002. To characterize the reasons for these 2 exceptions, the absolute concentrations of biomass and fossil carbon, derived by multiplication of pMC and carbon concentrations in $\mu \mathrm{m} / \mathrm{m}^{3}$ for each size fraction, are calculated (Figure 2). Carbon concentrations were calculated with information of the $\mathrm{CO}_{2}$ pressure generated during purification process as was previously mentioned. As indicated in the figure, the elevated pMC in the coarse fraction $(>7.9 \mu \mathrm{m})$ in April and October 2003 may result from an excess of biomass carbon with the constant fossil levels compared to other months. This elevation could be attributed to the coarse particles of biological origin, such as pollens observed by the SEM (Figure 3), and identified as those of the Japanese cedar and oak species. We also observed a seasonal trend in the frequency distribution of pollens in the $>7.9-\mu \mathrm{m}$ fraction (Figure 4). Whereas the fossil carbon concentrations were quite constant through all samples, with the exception of December 2002, the results from our SEM observations semi-quantitatively indicated that pollens might increase pMC values in the coarse fraction in April and October 2002.

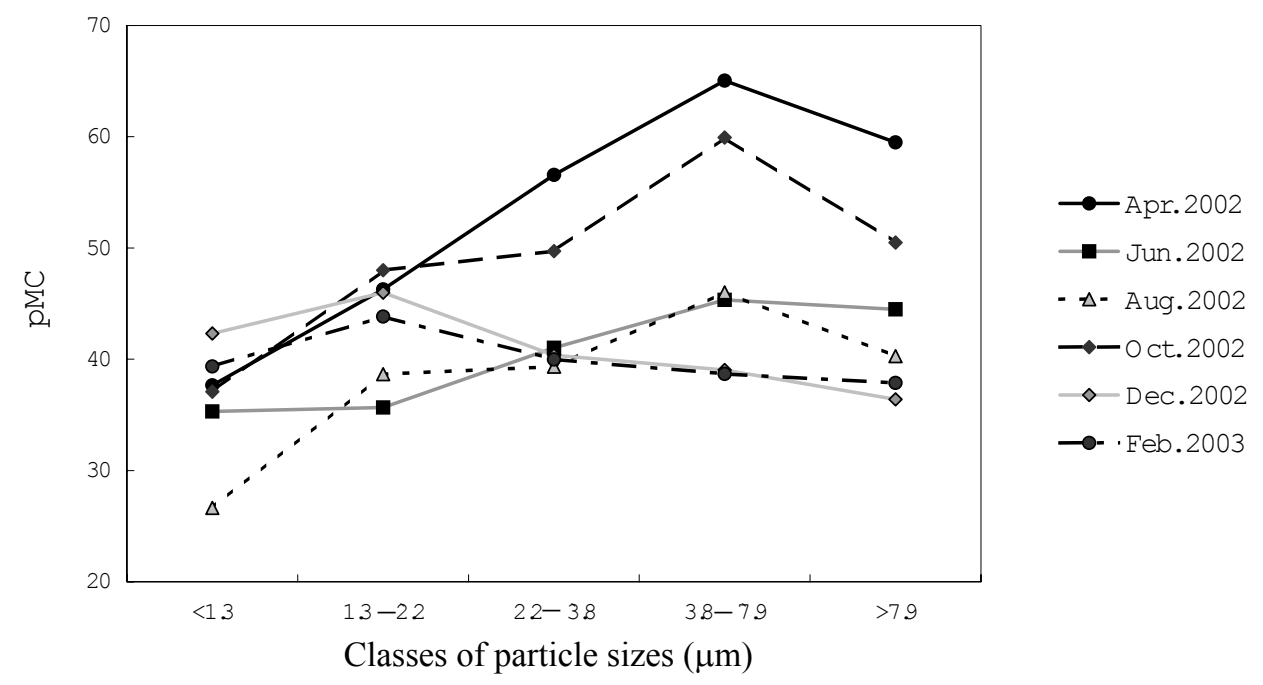

Figure 1 Temporal variations of ${ }^{14} \mathrm{C}$ concentrations

A relatively low pMC value was observed in the finest particle fraction in August (Figure 1) due to the larger amount of fossil carbon (Figure 2). There were no clear tendencies of increased production of electricity or traffic density in this month. This might be attributed to the increased volatilization of VOCs from anthropogenic sources (e.g. asphalt surface) due to the hot weather in Tokyo in this season, which could result in the increased formation of fine secondary particles by atmospheric condensation. Further investigation is necessary to clarify the cause of this variation.

The pMC of the elemental carbon in the APM is currently under investigation to identify the combustion sources from either fossil or biomass origins using elemental carbon as an indicator of the combustion sources. We conclude from the results of the present study that the analysis of temporal 

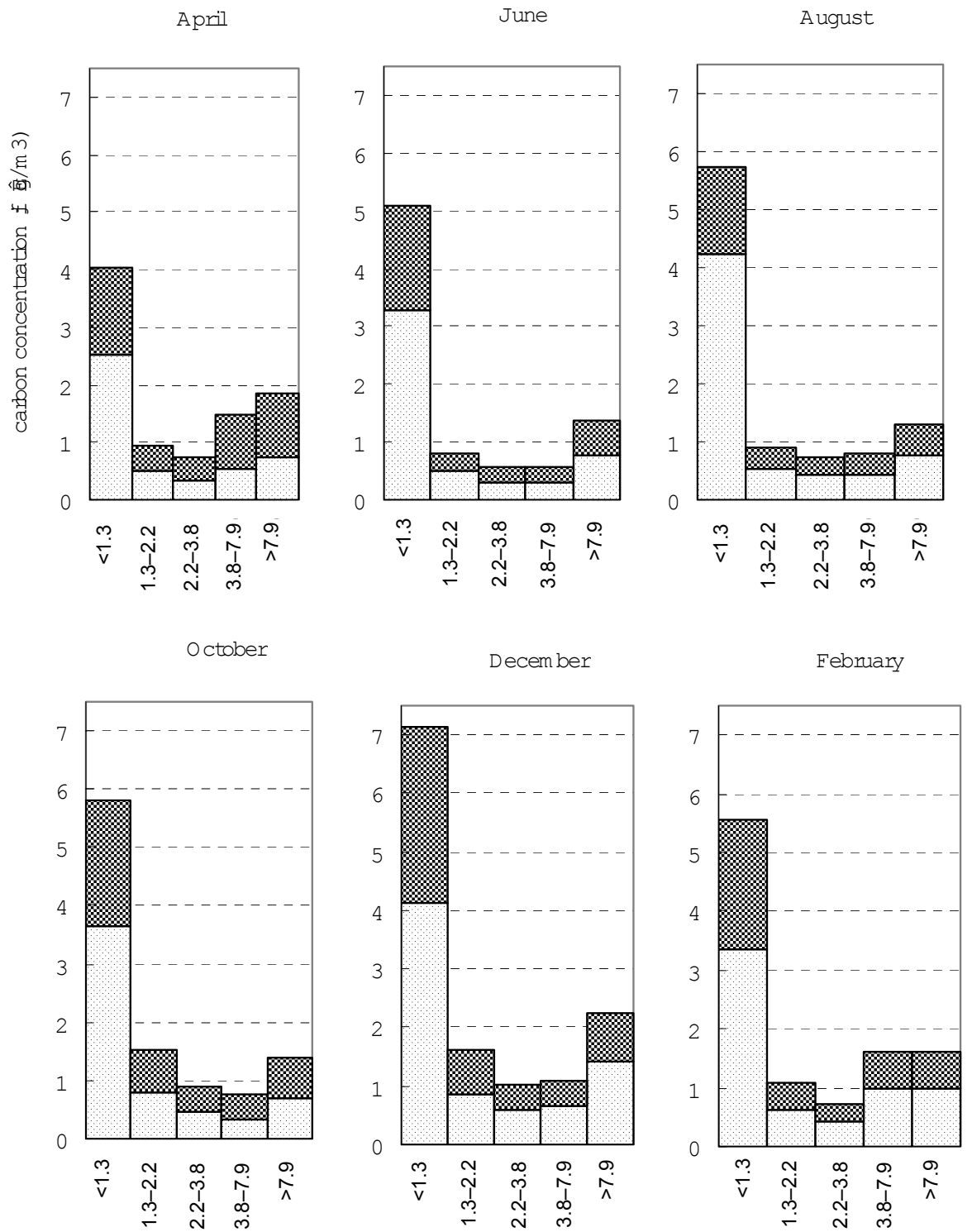

\section{Classes of particle sizes $[\mu \mathrm{m}]$}

Figure 2 Temporal variations of the concentrations of biomass (dark) and fossil carbons (light) 


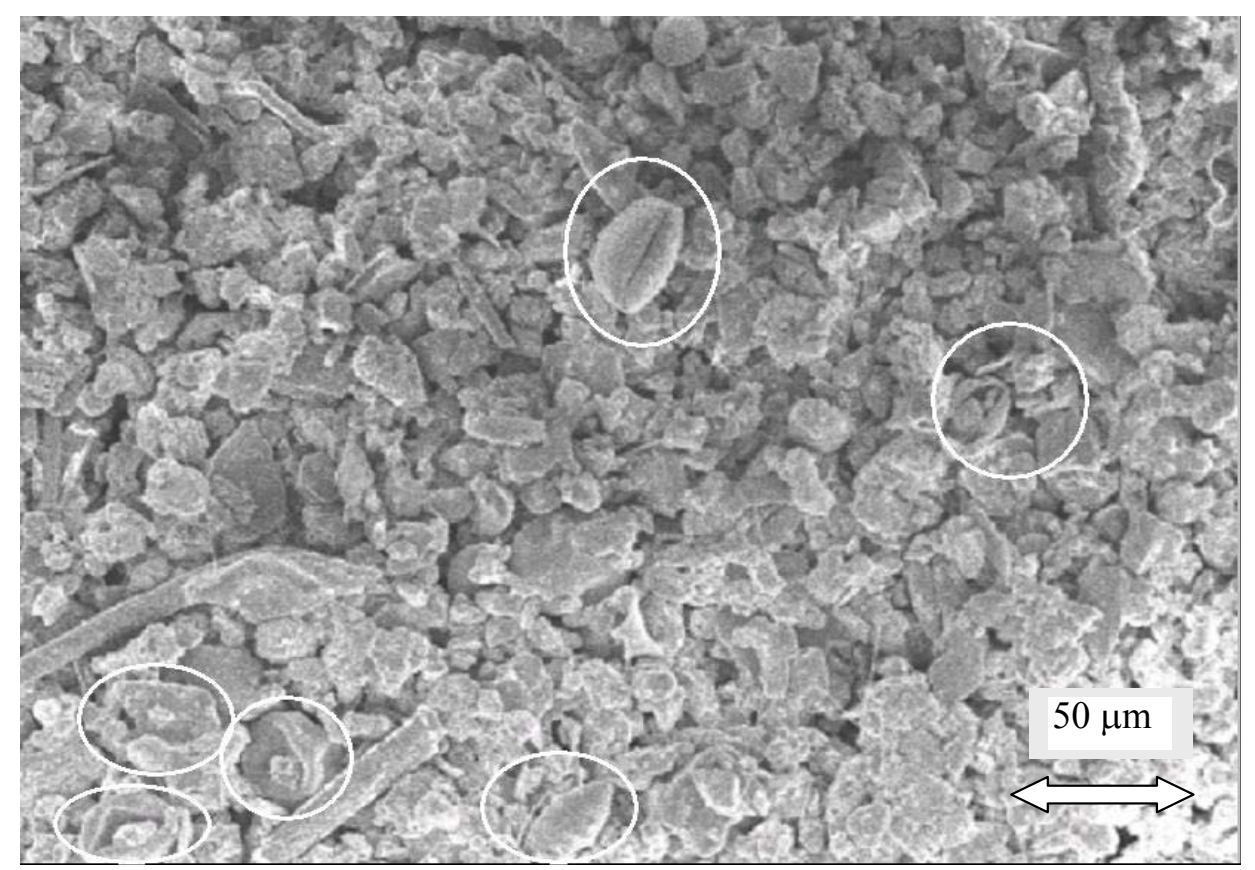

Figure 3 APM $(>7.9 \mathrm{pm})$ collected in April $2002(325 \times 225 \mu \mathrm{m})$

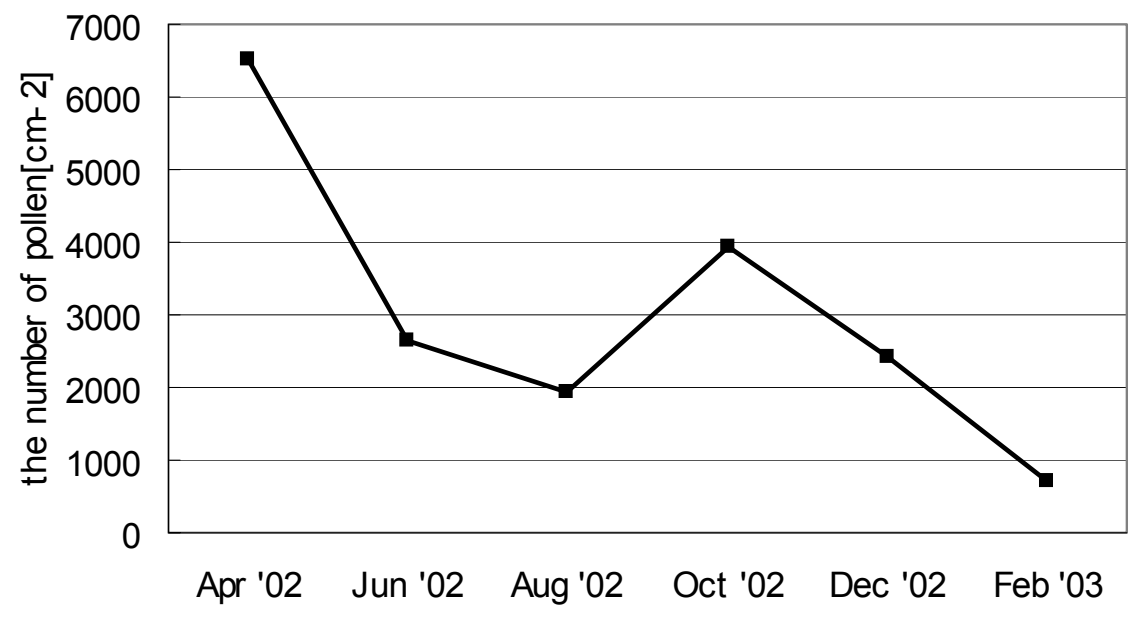

Figure 4 Number of pollen grains on the filter $(>7.9 \mu \mathrm{m})$

and across size-fraction variations can be an effective approach to generate hypotheses regarding source(s) of carbonaceous particles in the APM.

\section{ACKNOWLEDGEMENTS}

The authors gratefully acknowledge Mr R Suzuki, Mr T Kobayashi, and Ms M Nakamura of the NIES for their technical assistance. The authors sincerely appreciate the work of Dr Sahashi, Toho University, for identifying the species of pollens in the APM. 


\section{REFERENCES}

Charlson RJ, Schwartz SE, Hales JM, Cess RD, Coakley JA, Hansen JE, Hofmann DJ. 1992. Climate forcing by anthropogenic aerosols. Science 255:423-30.

Clayton G, Arnold J, Patty F. 1955. Determination of sources of particulate atmospheric carbon. Science 122:751-53.

Currie LA, Stafford TW, Sheffield AE, Klouda GA, Wise SA, Fletcher RA, Donahue DJ, Jull AJT, Linick TW. 1989. Microchemical and molecular dating. Radiocarbon 31(3):448-63.

Currie LA, Eglinton TI, Benner BA, Pearson A. 1997. Radiocarbon "dating" of individual chemical compounds in atmospheric aerosol: first results comparing direct isotopic and multivariate statistical apportionment of specific polycyclic aromatic hydrocarbons. Nuclear Instruments and Methods in Physics Research B 123:475-86.

Currie LA. 2000. Evolution and multidisciplinary frontiers of ${ }^{14} \mathrm{C}$ aerosol science. Radiocarbon 42(1):11526.

Dockery DW, Pope CA, Xu XP, Spengler JD, Ware JH, Fay ME, Ferris BG, Speizer FE. 1993. An association between air pollution and mortality in six U.S. cities. New England Journal of Medicine 329:1753-9

Gordon GE. 1988. Receptor models. Environmental Science and Technology 22:1132-42.

Hildemann LM, Klinedinst DB, Klouda GA, Currie LA, Cass GR. 1994. Sources of urban contemporary carbon aerosol. Environmental Science and Technology 28:1565-76.

Kitagawa H, Masuzawa T, Nakamura T, Matsumoto E. 1993. A batch preparation method for graphite targets with low-background for AMS C-14 measurements. Radiocarbon 35(2):295-300.

Klinedinst DB, Currie LA. 1999. Direct quantification of PM2.5 fossil and biomass carbon within the Northern Front Range Air Quality Study's domain. Environmental Science and Technology 33:4146-54.

Lemire KR, Allen DT, Klouda GA, Lewis CW. 2002. Fine particulate matter source attribution for southeast Texas using ${ }^{14} \mathrm{C} /{ }^{13} \mathrm{C}$ ratios. Journal of Geophysical Research 107:4613. doi: 10.1029/2002JD002339.

Reddy CM, Pearson A, Xu L, McNichol AP, Benner Jr. BA, Wise SA, Klouda GA, Currie LA, Eglinton TI. 2002. Radiocarbon as a tool to apportion the sources of polycyclic aromatic hydrocarbons and black carbon in environmental samples. Environmental Science and Technology 36:1774 -82.

Stuiver M, Polach HA. 1977. Discussion: reporting of ${ }^{14} \mathrm{C}$ data. Radiocarbon 19(3):355-63.

Tanaka A, Yoneda M, Uchida M, Uehiro T, Shibata Y, Morita M. 2000. Recent advances in ${ }^{14} \mathrm{C}$ measurement at NIES-TERRA. Nuclear Instruments and Methods in Physics Research B 172:107-11.

Weissenbök RH, Currie LA, Gröllert C, Kutschera W, Marolf J, Priller A, Puxbaum H, Rom W, Steier P. 2000. Accelerator mass spectrometry analysis of nonsoluble carbon in aerosol particles from high alpine snow (Mt. Sonnblick, Austria). Radiocarbon 40(1): 285-94.

Yoshizumi K. 1991. Source apportionment of aerosols in the Tokyo metropolitan area by chemical element balances. Energy and Buildings 15-6: 711-7. 